\title{
Developmental Toxicity of Carbon Quantum Dots to the Embryos/Larvae of Rare Minnow (Gobiocypris rarus)
}

\author{
Yuan-Yuan Xiao, Li Liu, Yao Chen, Yu-Lian Zeng, Ming-Zhi Liu, and Li Jin \\ Key Laboratory of Freshwater Fish Reproduction and Development, Key Laboratory of Aquatic Science of Chongqing, \\ School of Life Sciences, Southwest University, Ministry of Education, Chongqing 400715, China
}

Correspondence should be addressed to Li Jin; jinll@swu.edu.cn

Received 15 July 2016; Accepted 20 September 2016

Academic Editor: Kaiyu He

Copyright (C) 2016 Yuan-Yuan Xiao et al. This is an open access article distributed under the Creative Commons Attribution License, which permits unrestricted use, distribution, and reproduction in any medium, provided the original work is properly cited.

\begin{abstract}
The toxic effects of CDs on rare minnow (Gobiocypris rarus) embryos at different developmental stages were investigated. The results showed that rare minnow embryos had decreased spontaneous movements, body length, increased heart rate, pericardial edema, yolk sac edema, tail/spinal curvature, various morphological malformations, and decreased hatching rate. Biochemical analysis showed the CDs exposure significantly inhibited the activity of $\mathrm{Na}^{+} / \mathrm{K}^{+}$-ATPase and $\mathrm{Ca}^{2+}$-ATPase and increased the MDA contents and the activity of SOD, CAT, and GPX. Further examination suggested that the CDs exposure induced serious embryonic cellular DNA damage. Moreover, the CDs exposure induced upregulation of development related genes (Wnt8a and Mstn) along with the downregulation of Vezf1. Overall, the present study revealed that the CDs exposure has significant development toxicity on rare minnow embryos/larvae. Mechanistically, this toxicity might result from the pressure of induced oxidative stress coordinate with the dysregulated development related gene expression mediated by the CDs exposure.
\end{abstract}

\section{Introduction}

Carbon quantum dots (CDs) denote a class of less than $10 \mathrm{~nm}$ sized nanoparticles composed of carbon, hydrogen, oxygen, nitrogen, and other elements [1]. Bearing the advantage as higher thermostability, photostability, quantum yield, and lower release rate of heavy metal ions than the traditional semiconductor quantum dots [2], CDs have been proposed broadly to the potential application in analytical chemistry, biological probing and imaging, drug delivery, and so forth [3-5]. Further, with the advent of nanotechnology, CDs are becoming more prevalent in the environment. This raises increasing public concerns about biosafety and the potential health risks of long term exposure to CDs. Previous study has shown that concentration of the $\mathrm{TiO}_{2}$ in surface waters is $21 \mathrm{ng} / \mathrm{L}$ and the $\mathrm{C}_{60}$ in sewage is $4 \mathrm{ng} / \mathrm{L}$, which could increase to $35 \mathrm{mg} / \mathrm{L}$ through the suspension process in the natural water system [6]. Further, a series of studies has shown the nanomaterials including $\mathrm{CdSe} / \mathrm{ZnS}$ and $\mathrm{TiO}_{2}$ could induce the fishes embryos' developmental defect such as embryonic pericardial edema, yolk sac edema, and tail malformation [7], suggesting the potential risky impact of $\mathrm{CDs}$ on the natural water ecosystem. Thus, the biological and environmental toxicity of CDs gradually attracted great research interest which is required for the safety evaluation for further application.

However, only limited studies regarding this issue have been reported while the comprehensive toxic effects and the exact underlying mechanism are still not clear. In $16 \mathrm{HBE}$ cells, high concentration of CDs treatment results in oxidative damage and decreased proliferation rate. Besides, CDs could form a complex with BSA leading to the structural alteration of some functional proteins [8]. In animal models, when CDs were administrated through the tail vein injection in rats, the oxidative damage and the disrupted immunologic balance were observed in the target organs which eventually induced the compensable pathological lesions [9].

Here we report a biosafety research of $\mathrm{CDs}$ on rare minnow (Gobiocypris rarus), an endemic cyprinid fish in China [10]. With serious features such as short life cycle, high fertilization rates, and hatching rates, rare minnow has 
TABLE 1: Primers sequences used for real-time PCR.

\begin{tabular}{lrr}
\hline Gene & Forward primers & Reverse primers \\
\hline$\beta$-Actin & CCCCATTGAGCACGGTATTG & GGGAGCCTCTGTGAGCAGGA \\
Wnt $8 a$ & CCAAAGGCTTACCTCACA & AACCCAACCACGACCC \\
Vezfl & GTGGCGGGCATCCTCACCAC & GCCGCACATCTCACAGCCGT \\
\hline
\end{tabular}

been regarded as one of the suitable aquatic organisms for the biological toxicity assessment [11].

In our study, we have investigated the developmental toxicity of the CDs on the embryos/larvae of rare minnow. Our data would not only enrich the scientific understanding for the biocompatibility and risk assessment of CDs, but also promote the early diagnosis of potential pollution in fishery water area introduced by nanomaterials.

\section{Materials and Methods}

2.1. CDs. CDs (W-900-440) were purchased from Beida Jubang Science \& Technology Co. Ltd. (Beijing, China). Monodispersed CDs were $2-6 \mathrm{~nm}$ sized and prepared as $10 \mathrm{mg} / \mathrm{mL}$ (water solution). The fluorescence emission wavelength of the CDs is $440 \mathrm{~nm}$.

2.2. Fish Husbandry and Embryo Collection. Sexually matured and healthy rare minnow were selected as parent fish. Following long term acclimation (more than 4 weeks) in the circulating water system with the sex ratio as $1: 1$, the spawning time points were set to 20:00 daily through the circadian rhythm manipulation. Once the sexual chasing behavior of the parent fishes was observed, the fertilized eggs were collected followed by artificial insemination (fertilization rate > 95\%). The parent fishes were fed three times daily to visual satiation (twice with commercial granular food and once with fairy shrimp). Culture condition was set as $25 \pm 1^{\circ} \mathrm{C}$ with the daily photoperiod cycle as $12: 12$ (light : dark).

2.3. Embryo Toxicity Assay. The toxicity assay was designed according to the established protocol [12]. Briefly, the rare minnow embryos were collected immediately after fertilization; at blastocyst stage, normal embryos were selected and introduced individually into 24 -well plates filled with $1 \mathrm{~mL} /$ well daily renewed solutions or controls per well. The plates were incubated at $25 \pm 1{ }^{\circ} \mathrm{C}$ in water bath for $96 \mathrm{~h}$ with the photoperiod of $12: 12 \mathrm{~h}$ (light: dark). The toxicity effects of CDs on the subsequent embryonic development of rare minnow were evaluated by exposing fertilized eggs to a range of concentrations $(0,1,5,10,20,40$, and $80 \mathrm{mg} / \mathrm{L})$. The standard dilution solution served as the control. Three wells for concentration groups and three replicates were set for the tests, with 20 embryos per replicate. In our study, embryos/larvae from the five early embryonic development stages (12 hpf, $24 \mathrm{hpf}, 48 \mathrm{hpf}, 72 \mathrm{hpf}$, and $96 \mathrm{hpf}$ ) were sampled and analyzed.
2.4. Microexamination. The developmental parameters were monitored and documented every six hours between $12 \mathrm{hpf}$ (hours after fertilization) and $96 \mathrm{hpf}$. Toxicological endpoints were determined by the observation through microscopy (Nikon SMZ 25, Japan). Between $12 \mathrm{hpf}$ and $96 \mathrm{hpf}$ stage, the hatching rate, the mortality rate, and the malformation rate were calculated. The spontaneous movement frequency at $36 \mathrm{hpf}$ stage and the heart rate at $60 \mathrm{hpf}$ stage were calculated, respectively, as well. The body length $(\mathrm{mm})$, the area of pericardial edema $\left(\mu \mathrm{m}^{2}\right)$, area of sac-yolk edema $\left(\mu \mathrm{m}^{2}\right)$, and SVBA distance $(\mu \mathrm{m})$ at $96 \mathrm{hpf}$ stage were photographed with a digital camera and measured from these digital images using Image pro plus 6.0 software (Media Cybernetics, America).

2.5. Measurement of Antioxidant Enzymes, $\mathrm{Na}^{+} / \mathrm{K}^{+}$-ATPase, $\mathrm{Ca}^{2+}$-ATPase Activity, and Malondialdehyde (MDA) Content. 20 embryos/larvae were collected from each group. Each sample was defrosted and homogenized on ice with $0.65 \%$ ice-cold saline. Following centrifuging at $2500 \times \mathrm{g}$ at $4^{\circ} \mathrm{C}$ for $10 \mathrm{~min}$, the supernatants were collected and subject to the measurement of the MDA content and the activity of the antioxidant enzymes, $\mathrm{Na}^{+} / \mathrm{K}^{+}$-ATPase, $\mathrm{Ca}^{2+}$-ATPase based on the kits manual (Nanjing Jiancheng Bioengineering Institute, Nanjing, China).

2.6. Comet Assay. 20 embryos/larvae were collected from each group. Samples were completely digested in $37^{\circ} \mathrm{C}$ water bath with $0.25 \%$ trypsin. Following centrifuging at $2500 \times \mathrm{g}$ for $10 \mathrm{~min}$ and the supplementation with moderate amount of PBS ( $\mathrm{pH} 7.4)$, the single-cell suspension $\left(10^{4}-10^{6} / \mathrm{mL}\right)$ was prepared and subject to the single-cell gel electrophoresis (SGCE). For each treatment group, about 100 cells per slide were randomly scored with an image analysis through fluorescent microscopy. The comet images were analyzed by the auto comet image analysis system [13]. The DNA damage of the samples was evaluated by comet tail length, percentage of total DNA in the tail, tail moment, and olive tail moment.

2.7. Gene Expression Analysis. According to the gene sequences in GenBank, primers were designed by the primer 5.0 software (Table 1) and synthesized by biotechnology company (Invitrogen). The total RNA of tested rare minnow embryos/larvae was extracted using the RNAiso Plus (Takara, Kyoto, Japan). The total RNA contents were determined by measuring the absorbance at $260 \mathrm{~nm}$ and the RNA quality was verified by the ratio of the absorbance at $260 / 280 \mathrm{~nm}$ (range within 1.8 2.0). The first-strand cDNA synthesis was 


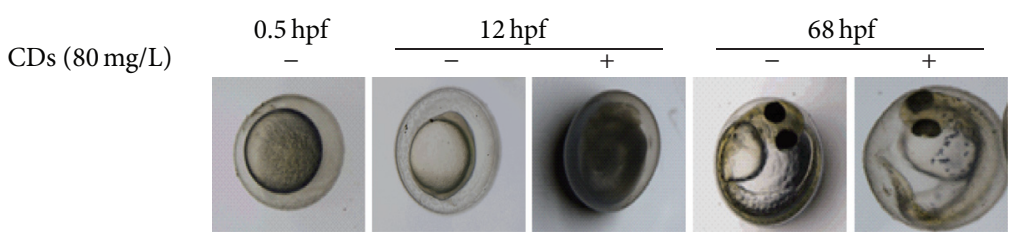

(a) Effects of exposure to CDs on developing rare minnow embryos

\begin{tabular}{|c|c|c|c|c|c|c|c|}
\hline \multirow[b]{2}{*}{ CDs: } & \multicolumn{7}{|c|}{$96 \mathrm{hpf}$} \\
\hline & $0 \mathrm{mg} / \mathrm{L}$ & $1 \mathrm{mg} / \mathrm{L}$ & $5 \mathrm{mg} / \mathrm{L}$ & $10 \mathrm{mg} / \mathrm{L}$ & $20 \mathrm{mg} / \mathrm{L}$ & $40 \mathrm{mg} / \mathrm{L}$ & $80 \mathrm{mg} / \mathrm{L}$ \\
\hline
\end{tabular}

(b) Effects of exposure to CDs on developing rare minnow larvae

FIGURE 1: Effects of exposure to CDs on developing rare minnow embryos/larvae.

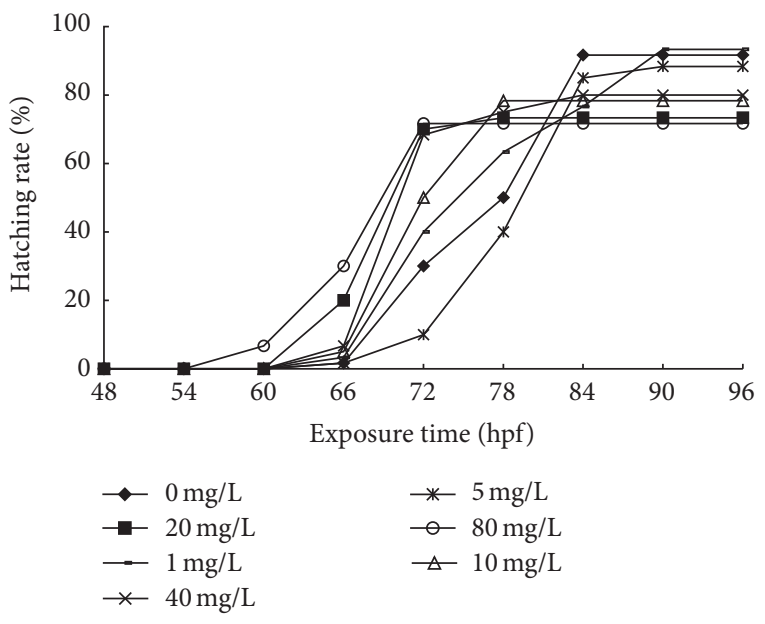

(a)

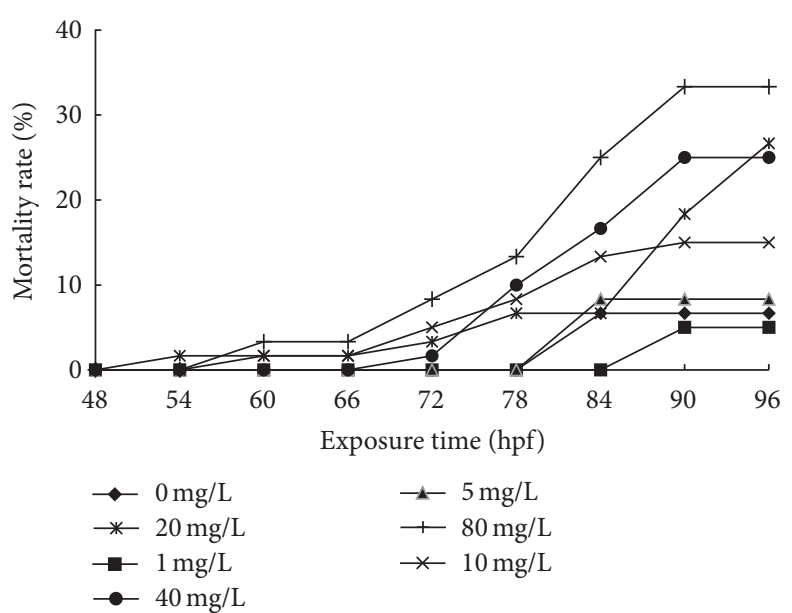

(b)

FIGURE 2: The hatching rate and mortality rate of rare minnow embryos exposed to different CDs concentration. The hatching rate (a) and mortality rate (b) for rare minnow embryos exposed to different CDs concentration. Triplicates were set for the tests, with 20 embryos/larvae each time.

performed by using PrimeScript ${ }^{\circledR}$ RT reagent Kit with gDNA Eraser (Takara, Kyoto, Japan) following the manufacturer's instruction. The qPCR results were calculated using $2^{-\Delta \Delta C T}$ method [14].

2.8. Statistical Analysis. Statistical analysis was conducted with the one-way ANOVA or $t$-test depending on heterogeneity of variance (SPSS 17.0). Following the one-way ANOVA analysis, LSD multiple range test was employed for the evaluation between control and treated groups; otherwise $t$-test was performed between control and treated groups because of heterogeneity of variance. The differences were considered significant at $p<0.05$ and extremely significant at $p<0.01$.

\section{Results}

3.1. Morphological and Behavioral Analysis of Embryo Development of Rare Minnow. The toxicity effect of CDs on rare minnow embryos/larvae at different developmental stage was investigated in a concentration-dependent manner. As shown in Figure 1(a), in the stage of $12 \mathrm{hpf}$, no obvious developmental defects were observed in lower concentration groups $(1,5,10$, and $20 \mathrm{mg} / \mathrm{L})$ compared with the control group. In higher concentration groups $(40 \mathrm{mg} / \mathrm{L}$ and $80 \mathrm{mg} / \mathrm{L})$, embryos yolk turbidity/agglutination was observed. Moreover, longer exposure time increased the malformation rate indicated by the shorter body length, tail/spinal curvature and pericardial edema, and yolk sac edema of the rare minnow embryos/larvae (Figure 1(b)).

The effects of CDs on hatching rate and mortality rate in embryos of rare minnow were tested. As shown in Figure 2, compared with the control group, the highest CDs concentration resulted in accelerated hatching. The hatched larvae were firstly observed at the stage of $54 \sim 60 \mathrm{hpf}$ in the highest concentration group while they were detected at the stage of $60 \sim 66 \mathrm{hpf}$ in control group. The hatching rate decreased significantly in response to the CDs treatment (Figure 2(a)). When the exposure time was extended to $96 \mathrm{hpf}$, most of unhatched embryos died. 
TABLE 2: Effects of CDs on behavior and morphological parameter measurement of rare minnow embryos/larvae.

\begin{tabular}{|c|c|c|c|c|c|c|c|}
\hline Indicator & $0 \mathrm{mg} / \mathrm{L}$ & $1 \mathrm{mg} / \mathrm{L}$ & $5 \mathrm{mg} / \mathrm{L}$ & $10 \mathrm{mg} / \mathrm{L}$ & $20 \mathrm{mg} / \mathrm{L}$ & $40 \mathrm{mg} / \mathrm{L}$ & $80 \mathrm{mg} / \mathrm{L}$ \\
\hline $\begin{array}{l}\text { Spontaneous } \\
\text { movements of } \\
36 \mathrm{hpf} \text { (bends/ } 30 \\
\text { seconds) }\end{array}$ & $11.17 \pm 2.32$ & $9.50 \pm 1.52$ & $10.17 \pm 1.47$ & $8.17 \pm 2.79^{* *}$ & $6.83 \pm 1.94^{* *}$ & $7.83 \pm 1.17^{* *}$ & $9.17 \pm 1.17$ \\
\hline $\begin{array}{l}\text { Heart rate of } 60 \mathrm{hpf} \\
\text { (bends/30 seconds) }\end{array}$ & $67.00 \pm 2.45$ & $64.50 \pm 2.88$ & $60.67 \pm 4.17^{*}$ & $64.00 \pm 4.24$ & $75.50 \pm 3.27^{* *}$ & $70.67 \pm 5.74$ & $71.00 \pm 3.58$ \\
\hline $\begin{array}{l}\text { Malformation rate } \\
(\%)\end{array}$ & $5.00 \pm 1.00$ & $6.67 \pm 1.73$ & $8.33 \pm 1.73$ & $13.30 \pm 1.73^{* *}$ & $26.67 \pm 4.58^{* *}$ & $25.00 \pm 3.00^{* *}$ & $43.33 \pm 4.58^{* *}$ \\
\hline SV-BA $\left(\times 10^{2} \mu \mathrm{m}\right)$ & $1.90 \pm 0.19$ & $2.07 \pm 0.27$ & $2.15 \pm 0.28$ & $2.70 \pm 0.45^{* *}$ & $3.13 \pm 0.26^{* *}$ & $3.05 \pm 0.47^{* *}$ & $3.32 \pm 0.26^{* *}$ \\
\hline $\begin{array}{l}\text { Area of pericardial } \\
\text { edema }\left(\times 10^{4} \mu \mathrm{m}^{2}\right)\end{array}$ & $2.48 \pm 0.53$ & $2.60 \pm 0.65$ & $2.97 \pm 0.32$ & $4.05 \pm 0.67^{* *}$ & $5.43 \pm 0.64^{* *}$ & $5.50 \pm 0.97^{* *}$ & $5.55 \pm 0.75^{* *}$ \\
\hline $\begin{array}{l}\text { Area of sac-yolk } \\
\text { edema }\left(\times 10^{5} \mu \mathrm{m}^{2}\right)\end{array}$ & $2.44 \pm 0.10$ & $2.56 \pm 0.10$ & $2.42 \pm 0.22$ & $2.83 \pm 0.16^{* *}$ & $3.17 \pm 0.23^{* *}$ & $3.49 \pm 0.27^{* *}$ & $3.41 \pm 0.27^{* *}$ \\
\hline Body length (mm) & $3.11 \pm 0.21$ & $3.13 \pm 0.18$ & $3.16 \pm 0.11$ & $3.03 \pm 0.08$ & $2.96 \pm 0.14$ & $2.82 \pm 0.20^{* *}$ & $2.80 \pm 0.18^{* *}$ \\
\hline
\end{tabular}

Values are presented as mean \pm SD. Spontaneous movements, heart rate, SV-BA, area of pericardial edema, and area of sac-yolk edema $(n=6)$; body length $(n=7)$ and malformation rate $(n=60)$. Values that are significantly different from the control are indicated by asterisks (one-way ANOVA or $t$-test, ${ }^{*} p<0.05$, $\left.{ }^{* *} p<0.01\right)$

Consistently, the increased mortality rate was observed in a concentration-dependent manner following the exposure to CDs at the stage of $96 \mathrm{hpf}$. It is interesting to note that no significant change among all concentration group treatments was detected before $72 \mathrm{hpf}$ in contrast to the marked elevation of the mortality rate after $72 \mathrm{hpf}$ (Figure 2(b)). It suggested that $72 \mathrm{hpf}$ stage might be important for the fate determination of the rare minnow embryo development in response to the environmental stress introduced by the CDs.

The spontaneous embryonic movement at $36 \mathrm{hpf}$ stage decreased in a concentration-dependent manner after the exposure to CDs. In the 10,20 , and $40 \mathrm{mg} / \mathrm{L}$ groups, the spontaneous embryonic movements decreased significantly against control group $(p<0.01)$. At the $60 \mathrm{hpf}$ stage, the embryos heart rate in control group was $67.00 \pm 2.45$ beats per 30 seconds (mean \pm SD) (Table 2). Embryos heart rates increased significantly in $20 \mathrm{mg} / \mathrm{L}$ group $(p<0.01)$. In the 40 and $80 \mathrm{mg} / \mathrm{L}$ group, heart rates just increased slightly. The malformation rates were increased in a concentrationdependent manner after the CDs exposure at the stage of $96 \mathrm{hpf}$. In 10 80 mg/L concentration group, the malformation rate was significantly increased compared with that in the control group $(p<0.01)$.

We also investigated the effects of CDs on hearts development of rare minnow embryos. In the 1 and $5 \mathrm{mg} / \mathrm{L}$ concentration group, compared with control, no significantly changed SV-BA distance was detected $(p<0.05)$ while, in the $10 \sim 80 \mathrm{mg} / \mathrm{L}$ concentration groups, the SV-BA distance was significantly increased $(p<0.01)$. The significant enlarged area of pericardial edema and sac-yolk edema appeared, respectively, in proportion to the increasing CDs concentration. In groups with concentration higher than $10 \mathrm{mg} / \mathrm{L}$, the areas of pericardial edema and of sac-yolk edema were significantly decreased in comparison to control larvae $(p<$ $0.01)$.

In addition, high concentration CDs treatment resulted in body length alteration of the larvae. At the $96 \mathrm{hpf}$ stage, the larvae in control group have significantly shorter body length than that in higher concentration (40 and $80 \mathrm{mg} / \mathrm{L}$ ) groups (Table 2) $(p<0.01)$.

\subsection{Effects of CDs on $\mathrm{Ca}^{2+}$-ATPase and $\mathrm{Na}^{+} / \mathrm{K}^{+}$-ATPase Activ-} ity of Rare Minnow Embryos/Larvae. As shown in Figure 3, the activities of $\mathrm{Ca}^{2+}$-ATPase and $\mathrm{Na}^{+} / \mathrm{K}^{+}$-ATPase decreased in a concentration-dependent manner following exposure to CDs. In the highest concentration $(80 \mathrm{mg} / \mathrm{L})$ group, the $\mathrm{Ca}^{2+}$-ATPase activities were decreased to $43 \%, 28 \%, 33 \%$, and $25 \%$ of control at the stage of $12 \mathrm{hpf}, 48 \mathrm{hpf}, 72 \mathrm{hpf}$, and $96 \mathrm{hpf}$, respectively. Similarly, $\mathrm{Na}^{+} / \mathrm{K}^{+}$-ATPase activity decreased in a concentration-dependent manner following exposure to CDs. In the highest concentration $(80 \mathrm{mg} / \mathrm{L})$ group, the $\mathrm{Na}^{+} / \mathrm{K}^{+}$-ATPase activities were decreased to $40 \%$, $47 \%, 65 \%, 63 \%$, and $67 \%$ of control at the $12 \mathrm{hpf}, 24 \mathrm{hpf}$, $48 \mathrm{hpf}, 72 \mathrm{hpf}$, and $96 \mathrm{hpf}$ stage, respectively.

3.3. Development Related Genes Expression. We discuss the effects of CDs on the expression pattern of the development related genes. As shown in Figure 4, Wnt8a, Vezf1, and Mstn mRNA levels at different concentrations $(1,5,10,20,40$, and $80 \mathrm{mg} / \mathrm{L}$ ) were examined with $\beta$-actin gene as endogenous control. The values of the mRNA levels were assessed as the fold of control. At the $12 \mathrm{hpf}$ stage, Mstn and Wnt8a showed the increased expression while the Vezfl expression is downregulated in all concentration group.

At $24 \mathrm{bpf}$ stage, Mstn expression was upregulated. Further, with increasing of CDs concentration, these fold changes of Mstn expression showed the tendency as it rose up first and then went down. Further, with increasing concentration of CDs, Mstn expression showed the tendency as it rose up first and then went down. Wnt8a expression is upregulated. In 40 and $80 \mathrm{mg} / \mathrm{L}$ group, Wnt $8 a$ expression is significantly elevated compared to control $(p<0.05)$. In contrast, Vezfl expression is downregulated as the increased CDs concentration. In 


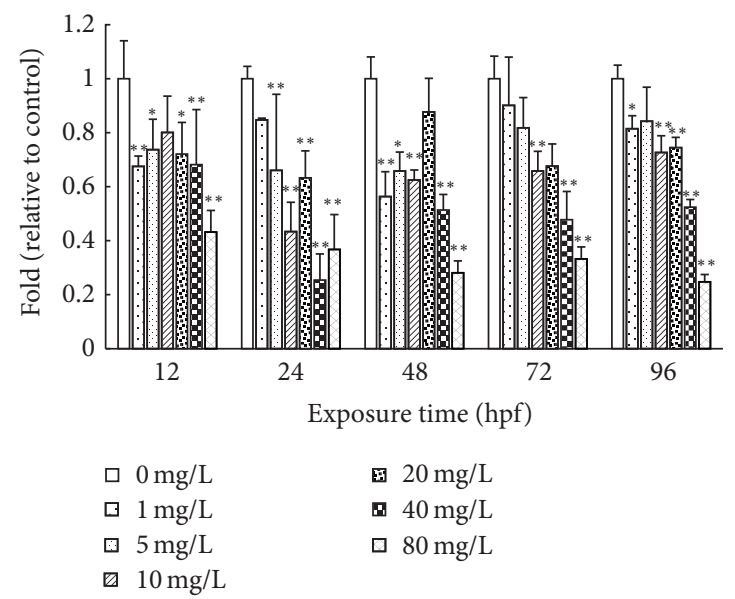

(a)

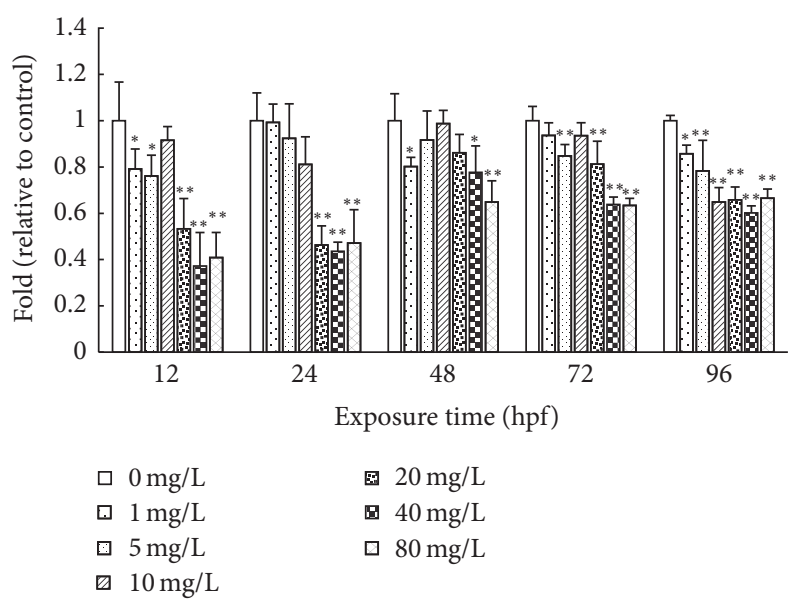

(b)

FIGURE 3: Effects of CDs on $\mathrm{Ca}^{2+}$-ATPase and $\mathrm{Na}^{+} / \mathrm{K}^{+}$-ATPase activity of rare minnow embryos/larvae. The $\mathrm{Ca}^{2+}-\mathrm{ATPase}(\mathrm{a})$ and $\mathrm{Na}^{+} / \mathrm{K}^{+}$ATPase (b) activities for rare minnow embryos exposed to different concentration of CDs. Values are presented as mean $\pm \operatorname{SD}(n=20)$. Values that are significantly different from the control are indicated by asterisks (one-way ANOVA or $t$-test, ${ }^{*} p<0.05,{ }^{* *} p<0.01$ ).

40 and $80 \mathrm{mg} / \mathrm{L}$ groups, Vezf1 expression is significantly decreased compared to control.

At later stage (48-96 hpf), Wnt8a expression is upregulated as the increased CDs concentration. In response to the treatment of $80 \mathrm{mg} / \mathrm{L} \mathrm{CDs}$, the Mstn expression level increased significantly in company with the marked decrease of Vezfl expression at $48 \mathrm{hpf}, 72 \mathrm{hpf}$, and $96 \mathrm{hpf}$ stage (Figure 4).

3.4. Effects of CDs on SOD, CAT, and GPX Activities and MDA Contents of Rare Minnow Embryos/Larvae. We also investigated the effects of CDs on SOD, CAT, and GPX activities and MDA contents of rare minnow embryos/larvae (Figure 5). The SOD activity increased with the extending exposure duration compared with control group except at the $72 \mathrm{hpf}$ stage. In the higher concentration $(20,40$, and $80 \mathrm{mg} / \mathrm{L})$ groups, significantly elevated SOD activity was detected compared with control $(p<0.05)$ (Figure 5(a)). The CAT activity alteration showed the similar pattern with that of SOD. With the extended exposure duration, significant higher CAT activity was detected accordingly (Figure 5(b)). GPX activity tended to rise up in relation to the increased CDs exposure duration. At each stage, higher CDs concentration treatment is induced sharply increase of the GPX activity $(p<$ 0.05 ) (Figure 5(c)). CDs exposure increased the MDA content significantly compared to control at each developmental stage. As the exposure time got longer, the MDA content showed the tendency of increase which was more prominent in higher concentration groups $(20,40$, and $80 \mathrm{mg} / \mathrm{L})(p<$ 0.01) (Figure 5(d)).

3.5. DNA Damage Analysis. Through comet assay, we examined if the CDs exposure would induce the DNA damage in embryonic cells. The results showed that CDs exposure induces the DNA damage in cells (Figure 6). At $72 \mathrm{hpf}$ stage, control cells showed uniform and regular round sized nucleus without tail (Figure 6(a)). In $1 \mathrm{mg} / \mathrm{L}$ concentration group, the cells showed oval nuclear staining without observed tail (Figure 6(b)). Elevated tail staining signal appeared in response to the increase of the CDs concentration (Figures $6(\mathrm{c})-6(\mathrm{~g}))$.

Further, we tested if the tail length staining in cells is proportion to the CDs concentration with which the cells were treated. As shown in Figure 7, CDs treatment promotes the tail formation in cells. In 20,40 , and $80 \mathrm{mg} / \mathrm{L}$ group, the tail length staining is significantly stronger than control $(p<0.01)$. Except in the low concentration groups $(1,5$, $10 \mathrm{mg} / \mathrm{L}$ ), longer CDs exposure time promotes the length and DNA content of the comet tail. At later stage ( $48 \mathrm{hpf}, 72 \mathrm{hpf}$, and $96 \mathrm{hpf}$ ), the length and DNA content of the comet tail increased in a concentration-dependent manner.

\section{Discussion}

4.1. Early Developmental Toxicity of CDs to Rare Minnow Embryos. A series of studies has shown the nanomaterials could induce the fish embryos' developmental defect among which the pericardial edema, yolk sac edema, and curvature of the spine appeared most frequently, suggesting the potential risky impacts of CDs on the natural water ecosystem.

Chen et al. have shown the abnormal condensation of embryonic eggs, pericardial edema, and curvature of the spine of zebrafish embryos/larvae following exposure to CdSe/ZnS QDs [15]. Kim and collogues showed that citratefunctionalized $\mathrm{TiO}_{2}$ nanoparticles caused pericardial edema, yolk sac edema, craniofacial malformation, and opaque yolk in zebrafish embryos [16]. Lv showed that nano-ZnO induced zebrafish embryonic pericardial edema, yolk sac edema, and tail malformation [17].

Consistently, our results showed the CDs exposure also induced the pericardial edema, yolk sac edema, and tail malformation in the embryos/larvae of rare minnow. These data confirm the conclusion that the nanoparticle exposure would induce the developmental defects of fish embryos/larvae. On 


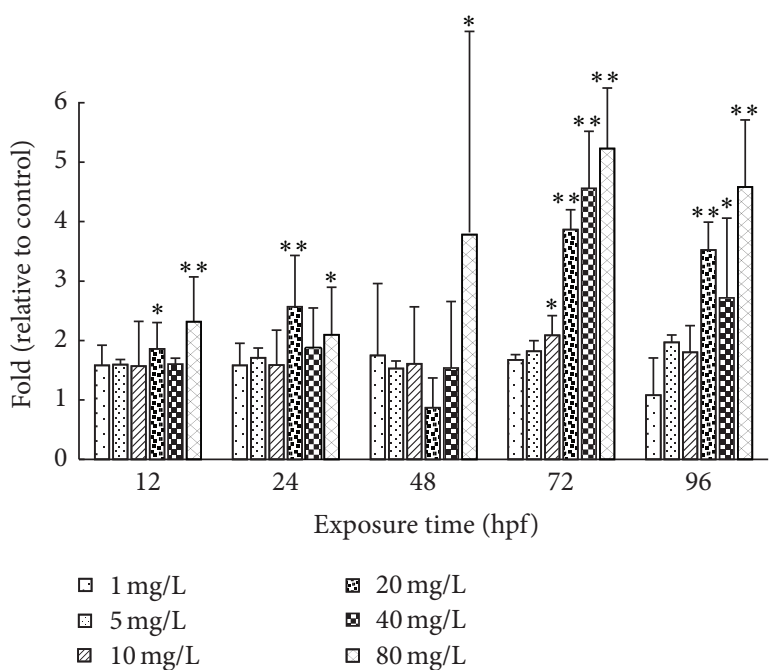

(a)

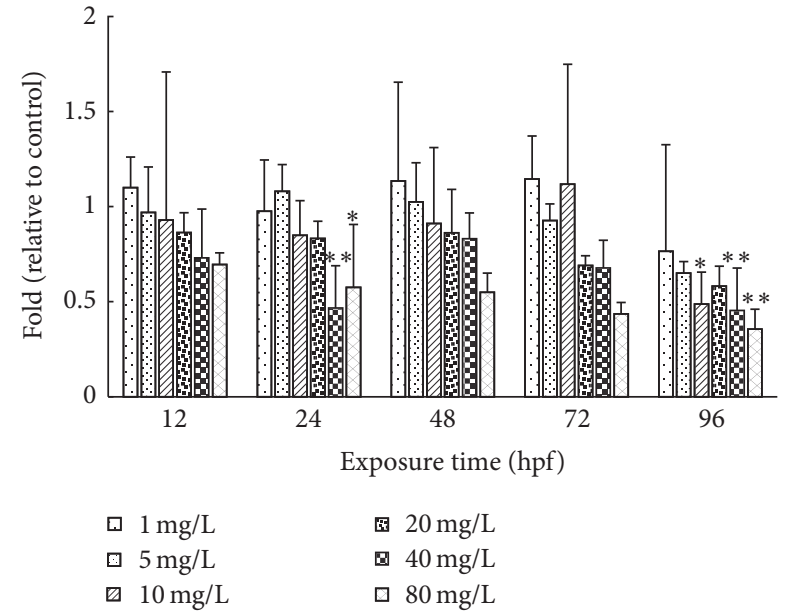

(b)

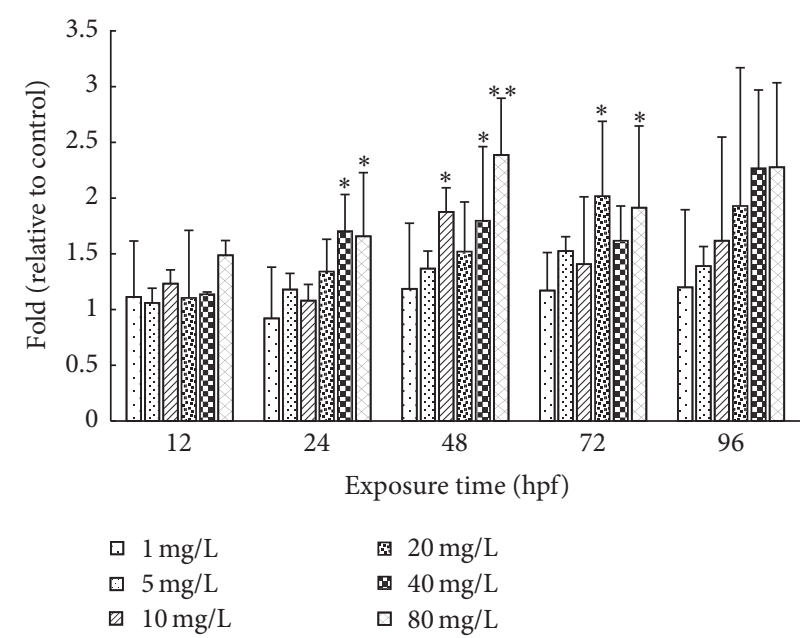

(c)

Figure 4: The Mstn, Vezfl, and Wnt8a mRNA levels for rare minnow embryos exposed to different concentration of CDs. The Mstn (a), Vezf1 (b), and Wnt8a (c) mRNA levels for rare minnow embryos exposed to different concentration of CDs. Values are presented as mean \pm SD $(n=15)$. Values that are significantly different from the control are indicated by asterisks (one-way ANOVA or $t$-test, ${ }^{*} p<0.05,{ }^{* *} p<0.01$ ).

the other, our data also suggest the pericardial edema, yolk sac edema, and tail malformation are the main consequences of nanoparticles exposure in different fish spices other than the zebrafish, implying the common potential environmental risk of the CDs and the possible dysregulated molecular mechanism of the conserved development pathway in fish embryos/larvae.

\subsection{Molecular Mechanism Underlined the Developmental} Defect Induced by the CDs Exposure. Providing energy for the active movements of $\mathrm{Na}^{+}$and $\mathrm{K}^{+}$across the cell membrane and the epithelia and $\mathrm{Na}^{+} / \mathrm{K}^{+}$-ATPase plays a central role in whole body osmoregulation, ionic transportation, muscle function, and several other membrane transportation dependent physiological processes. Previous study has reported that the activity of $\mathrm{Na}^{+} / \mathrm{K}^{+}$-ATPase is important for the growth and survival for the Penaeus vannamei in the postlarval stage [18]. Hill et al. showed the significant decreased malformation rate induced by TCDD through regulating the osmotic pressure balance of the zebrafish embryos [19], suggesting the correlation between the chemical induced hydropic malformation and osmoregulation. In our study, CDs treatment decreased the $\mathrm{Na}^{+} / \mathrm{K}^{+}$-ATPase activity in concentration-dependent manner (Figure 4(b)). It might block the pumping out of the $\mathrm{Na}^{+}$and subsequently break the balance of $\mathrm{Na}^{+}$accumulation, which eventually result in the edema and destruction of cells [20].

The hatching process of fish eggs was largely determined by the collaboration between hatching enzymes and membrane lipid peroxidation, which weakened the egg membrane along with embryos squirm [21]. In the majority of fishes, hatching enzyme is synthesized by the hatching gland distributed on the outer surface of embryo and yolk sac [22]. In our study, by means of interferometer spectrometer, we 


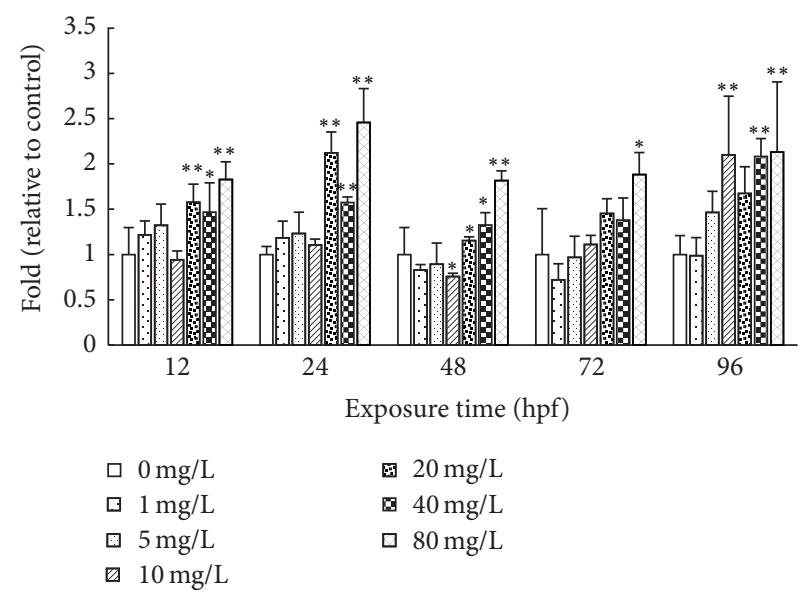

(a)

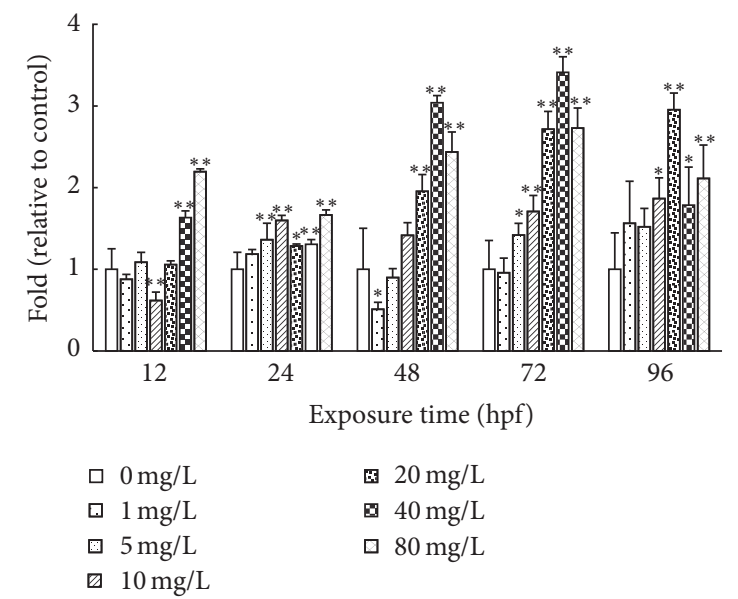

(c)

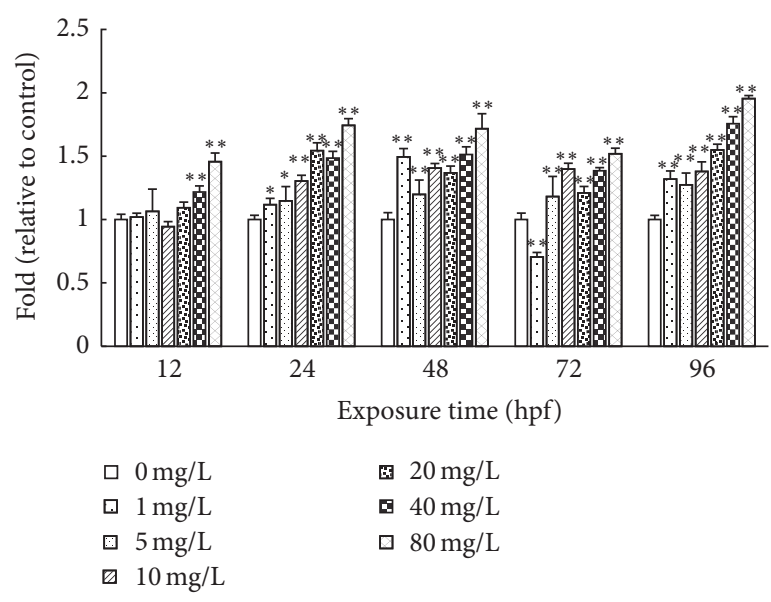

(b)

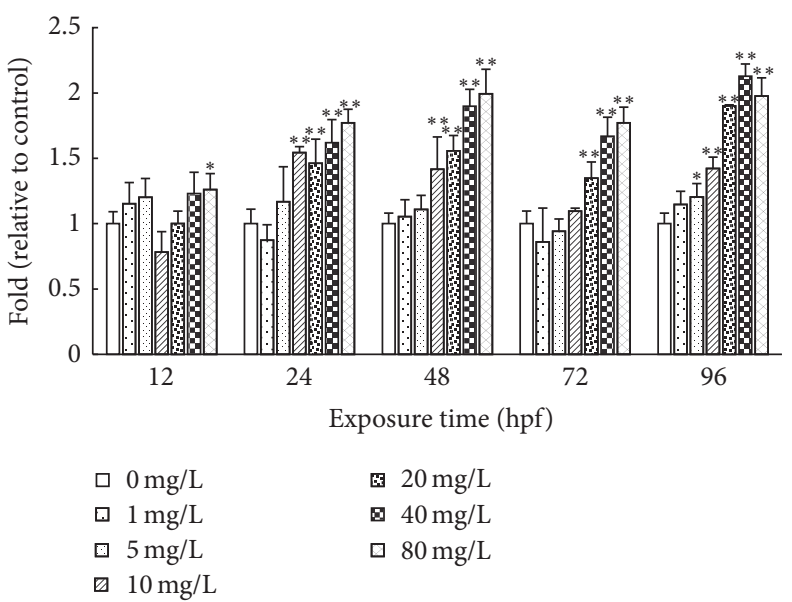

(d)

FIGURE 5: The SOD, CAT, and GPX activities and MDA contents for rare minnow embryos exposed to different concentration of CDs. The SOD (a), CAT (b), and GPX (c) activities and MDA contents (d) for rare minnow embryos exposed to different concentration of CDs. Values are presented as mean \pm SD $(n=20)$. Values that are significantly different from the control are indicated by asterisks (one-way ANOVA or t-test, $\left.{ }^{*} p<0.05,{ }^{* *} p<0.01\right)$.

did observe that, in rare minnow, the hatching gland cells were located on the surface of yolk sac (data not shown). Thus, the defective development of the yolk sac could trigger the inactivation of hatching gland. CDs could enter into the cytoplasm by endocytosis mechanism [23]. In addition, CDs could be complexed with proteins, polysaccharide, or other biological molecules in cells, which subsequently affect the hatching enzyme activity. It could explain the lower hatching rate result from the CDs treatment $(80 \mathrm{mg} / \mathrm{L})$.

In our study, the vascular endothelial zinc finger (Vezf1) expression level decreases with the increased CDs concentration (Figure 5(b)). Vezf1 participates in the molecular pathways that control early blood vessel development. Vezf1 may play an important role in the endothelial lineage determination and embryonic vasculogenesis and angiogenesis at later stages [24]. Silencing Vezf1 on chicken embryo in vivo suggested that Vezf1 is important for the development of blood vessel and heart [25]. Decreased expression levels of Vezf1 influenced the function of cardiovascular system during early development. Eventually, the heart physiological compensation promotes the increased heart rate and SV-BA distance of the embryos in $10 \sim 80 \mathrm{mg} / \mathrm{L}$ concentration group (Table 2).

In our study, the $\mathrm{Ca}^{2+}$-ATPase activities decreased with the increased $\mathrm{CDs}$ concentration and exposure duration (Figure 3(a)). The $\mathrm{Ca}^{2+}$-ATPase plays a crucial role in maintaining the intracellular concentration of $\mathrm{Ca}^{2+}[26]$. Inhibition of the activity of $\mathrm{Ca}^{2+}$-ATPase leads to the intracellular accumulation of $\mathrm{Ca}^{2+}$ which induces the skeletal developmental defect. Myostatin (Mstn) and Wnt8a expressions were observed to be upregulated significantly in response to the CDs treatments in a concentration-dependent manner (Figures 4(a) and 4(c)). Mstn belongs to the transforming growth factor-b (TGF-b) family and has been identified as an important negative regulator of muscle development [27].

MOD mediated muscle development is tightly regulated by the TGF- $\beta$ pathway. As the important transcriptional regulator of MOD, Mstn could be recruited by the SMAD 


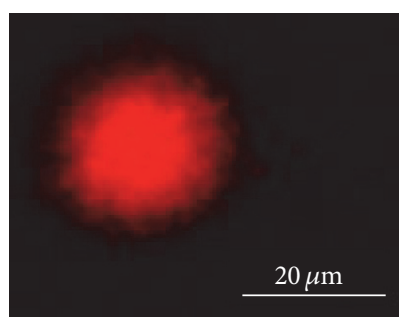

(a)

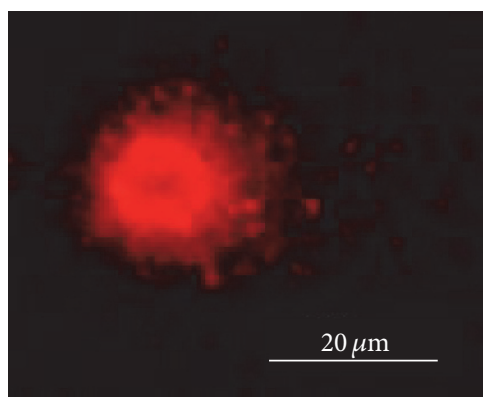

(e)

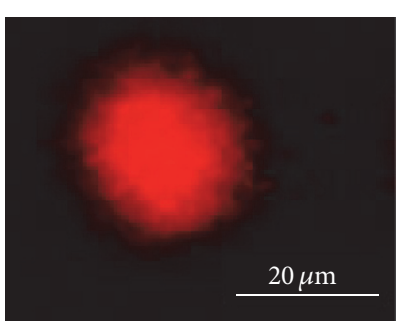

(b)

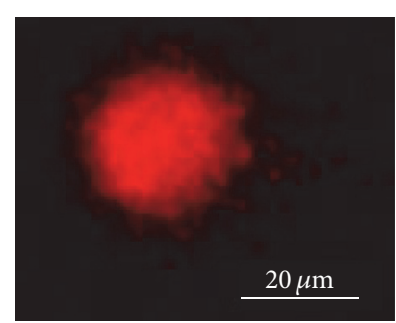

(c)

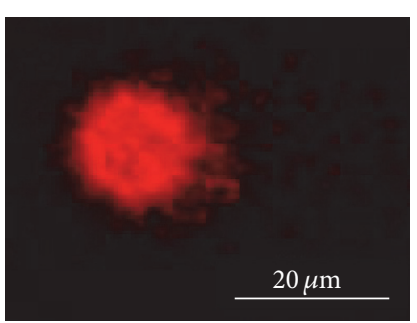

(d)

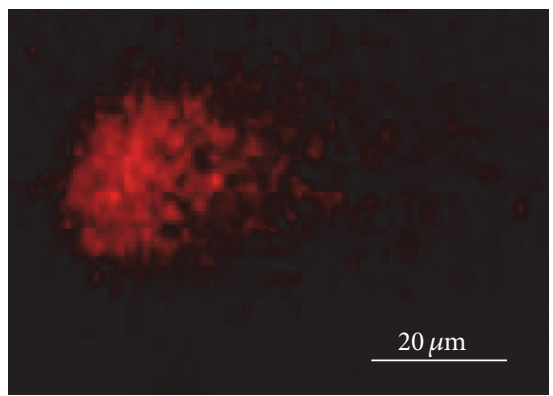

(f)

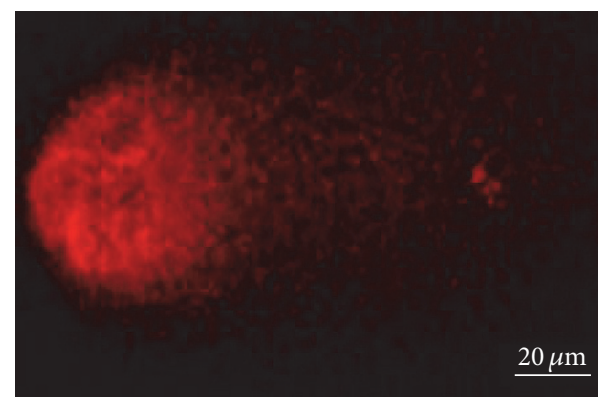

(g)

Figure 6: DNA damage. Effects of different concentration CDs (control (a), 1 mg/L (b), 5 mg/L (c), 10 mg/L (d), 20 mg/L (e), 40 mg/L (f), and $80 \mathrm{mg} / \mathrm{L}(\mathrm{g})$ ) on DNA damage of rare minnow embryos/larvae cells by comet assay.

proteins to the regulatory sequences of MOD which account for the retarded muscle growth [28]. Wnt8a is a key factor in Wnt/ $\beta$-catenin signaling pathway for the body axis extending [29]. Wnt8a initially locates at the bottom area of the animal pole of fertilized eggs which activate the classical Wnt $/ \beta$-catenin signaling through translocating to the destined microtube region, contributing to the curvature of the spine or tail within the development progression [30]. Downregulated Wnt8a results in lacking of the tail shaft structure in zebrafish embryos/larvae [31]. The significant increased expression of Wnt8a indicates the inhibited body axis extension. Taken together, on one hand, both of the Wnt8a expression upregulation and the inhibited $\mathrm{Ca}^{2+}$ ATPase activity promote the skeletal development and, on the other hand, increased Mstn expression blocks the muscle development which could explain the observed tail and spinal curvatures in this study.

It is noteworthy that the detailed mechanism underlined the CDs induced alteration of the target gene expression is poorly understood. Previous studies have shown that the CDs could be complexed with both double strand DNA (dsDNA) [32] and cellular functional proteins [9]. These results provide the probability that the CDs could affect the transcription of target gene through either cis- or transregulation. Accordingly, in our study, we reasoned that there are two possible mechanisms either working separately or together to alter the development related gene expression induced by CDs exposure: (1) the CDs might bind to the cis-elements which block the binding sites of transcriptional factors. (2) The CDs might be complexed with and dysregulated the transcriptional factors directly. However, the further study is needed to clarify this issue in the future.
4.3. Oxidative Stress and DNA Damage. Oxidative DNA damage and the inflammatory response by far are the two major involved mechanisms concerning the biological toxicity of the nanomaterials $[33,34]$. In normal physiological condition, the endogenous antioxidant enzymes combat the reactive oxygen species (ROS) and prevent the oxidative damage to the organism. In fact, fish can combat the oxidative stress with the enzyme system consisting of SOD, CAT, and GPX. SOD convert superoxide anions $\left(\mathrm{O}_{2}^{-}\right)$into $\mathrm{H}_{2} \mathrm{O}_{2}$ and then the enzymes of CAT and GPX catalyze the reaction to digest $\mathrm{H}_{2} \mathrm{O}_{2}$ into $\mathrm{H}_{2} \mathrm{O}$ and $\mathrm{O}_{2}{ }^{-}$[35]. Upon exogenous stress, abnormal ROS accumulation would break this balance and generate cellular oxidative damage.

Environmental pollutants go into the body and produce active oxygen free radicals through a series of metabolic conversions. If they are not cleared promptly, the balance will be destroyed and cause organisms oxidative damage [36]. LPO can be defined as the oxidative damage of cell membrane lipids and has been used extensively as a biomarker of oxidative stress in vivo [37]. As one of the main products of cell membrane LPO, MDA level has been regarded as the indicator of the LPO level [38].

In the present study, the activities of SOD were increased following CDs treatments (Figure 5(a)), suggesting the occurrence of the oxidative stress. SOD act first to scavenge the $\mathrm{O}_{2}{ }^{-}$; then antioxidant system becomes active to defense and synchronizes the activity of SOD with that of CAT. These results are in agreement with the previous study [39] in which the correlations between SOD and CAT were found in the mussel Mytilus galloprovincialis upon the stress introduced by copper nanoparticles exposure. Moreover, due to the accumulating $\mathrm{H}_{2} \mathrm{O}_{2}$ generated from $\mathrm{O}_{2}^{-}$by SOD, the CAT 


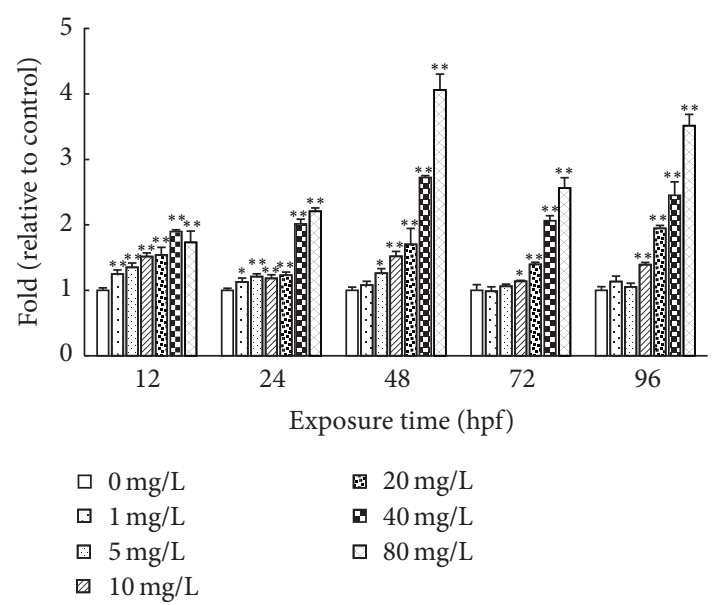

(a)

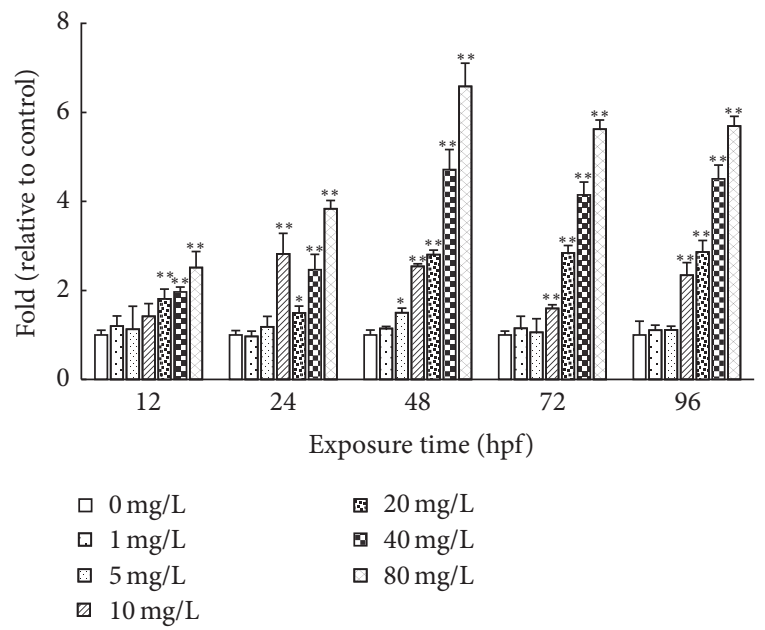

(c)

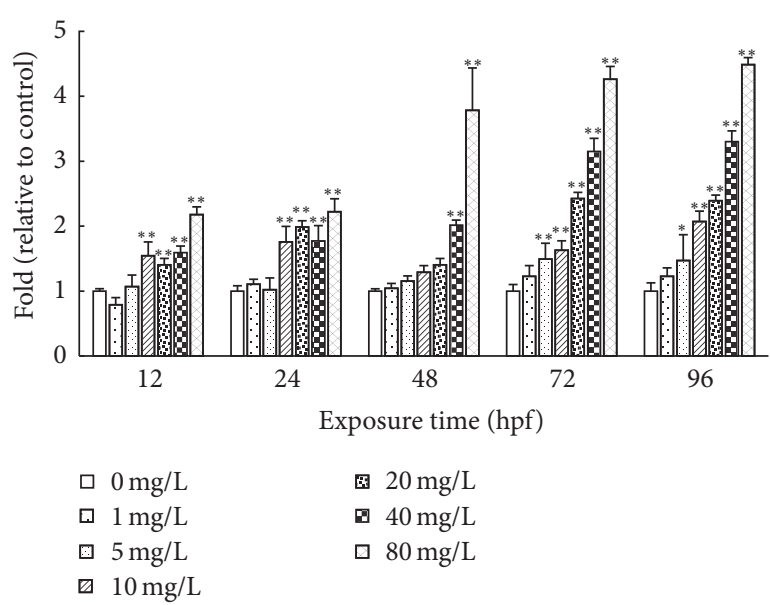

(b)

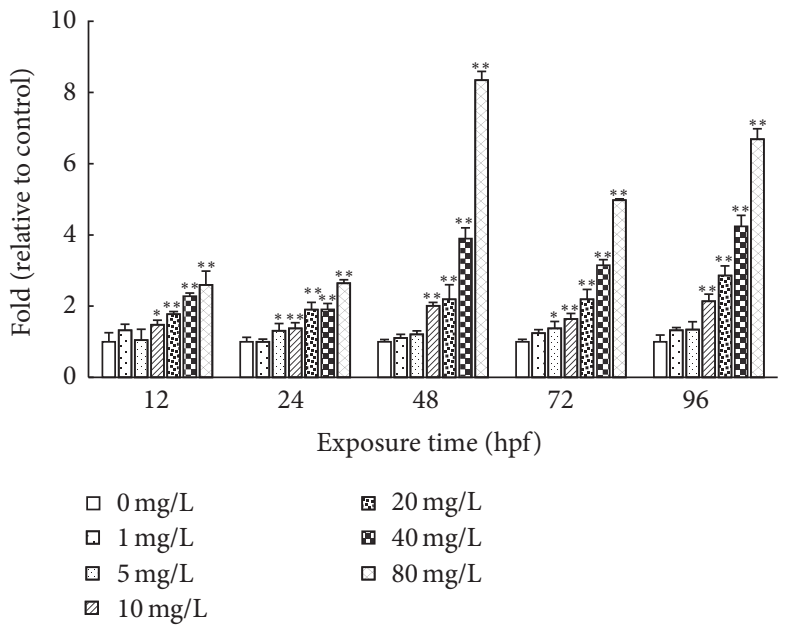

(d)

Figure 7: The comet tail length, tail DNA percent, tail moment, and olive tail moment for rare minnow embryos exposed to different concentration of CDs. The comet tail length (a), tail DNA percent (b), tail moment (c), and Olive tail moment (d) for rare minnow embryos exposed to different concentration of CDs. Values are presented as mean $\pm \mathrm{SD}(n=20)$. Values that are significantly different from the control are indicated by asterisks (one-way ANOVA or $t$-test, ${ }^{*} p<0.05,{ }^{* *} p<0.01$ ).

turn active quickly to keep pace with SOD (Figure 5(b)). Also, the GPX activity is induced by the higher intensity of stress result from higher CDs concentration (Figure 5(c)).

In sum, in rare minnow, the antioxidant enzyme system consists of SOD, CAT, and GPX combined together that act against oxidative stress and keep the MDA content in a certain range in lower $\mathrm{CDs}$ concentration group. However, long time of CDs exposure in 20,40 , and $80 \mathrm{mg} / \mathrm{L}$ concentration groups breaks the organism antioxidant capacity and results in the increase of the MDA content (Figure 5(d)), indicating that CDs exposure induced the oxidative stress to the embryo. Consequently, the defective development of rare minnow embryo appeared.

With the increased CDs concentration and extended exposure time, serious DNA damage of rare minnow embryos/larvae cells was detected (Figures 6 and 7). It could be the reason for higher malformation and mortality rate. Further increase of the CDs concentration results in more serious DNA damage induced by the ROS attacking nucleotides. The damaged DNA cannot be repaired in time; thus the malformation rate and mortality rate increased significantly [40].

\section{Conclusion}

(1) In summary, the higher concentrations of CDs have significant development toxicity on rare minnow embryos which could be characterized as decreased spontaneous movements and body length, increased heart rate, and pericardial edema, yolk sac edema and tail/spinal curvature, various morphological malformations, and decreased hatching rate.

(2) The underlying mechanism of this developmental toxicity appears to be related to the generation of oxidative stress, repressed DNA repair efficacy, and altered development related gene expression. 


\section{Competing Interests}

The authors declare that there is no conflict of interests regarding the publication of this paper.

\section{Acknowledgments}

The authors thank Dr. Haoxing Zhang and Dr. Xu Pang for the language editing of the manuscript. This work was supported by the Fundamental Research Funds for the Central Universities of China (XDJK2014C061 and XDJK2016E098).

\section{References}

[1] X. Wang, K. Qu, B. Xu, J. Ren, and X. Qu, "Multicolor luminescent carbon nanoparticles: synthesis, supramolecular assembly with porphyrin, intrinsic peroxidase-like catalytic activity and applications," Nano Research, vol. 4, no. 9, pp. 908920, 2011.

[2] L. Cao, M. J. Meziani, S. Sahu, and Y.-P. Sun, "Photoluminescence properties of graphene versus other carbon nanomaterials," Accounts of Chemical Research, vol. 46, no. 1, pp. 171-180, 2013.

[3] L. Ma, Study on the Synthesis of Carbon Nanodots and Its Application, Henan Normal University, Xinxiang, China, 2014.

[4] Y. Song, W. Shi, W. Chen, X. Li, and H. Ma, "Fluorescent carbon nanodots conjugated with folic acid for distinguishing folatereceptor-positive cancer cells from normal cells," Journal of Materials Chemistry, vol. 22, no. 25, pp. 12568-12573, 2012.

[5] C. Liu, P. Zhang, X. Zhai et al., "Nano-carrier for gene delivery and bioimaging based on carbon dots with PEI-passivation enhanced fluorescence," Biomaterials, vol. 33, no. 13, pp. 36043613, 2012.

[6] F. Gottschalk, T. Sonderer, R. W. Scholz, and B. Nowack, "Modeled environmental concentrations of engineered nanomaterials $\left(\mathrm{TiO}_{2}, \mathrm{ZnO}, \mathrm{Ag}, \mathrm{CNT}\right.$, fullerenes) for different regions," Environmental Science and Technology, vol. 43, no. 24, pp. 92169222, 2009.

[7] E. Oberdörster, S. Zhu, T. M. Blickley, P. McClellan-Green, and M. L. Haasch, "Ecotoxicology of carbon-based engineered nanoparticles: effects of fullerene $\left(\mathrm{C}_{60}\right)$ on aquatic organisms," Carbon, vol. 44, no. 6, pp. 1112-1120, 2006.

[8] X. Zhang, The Safety Applied Study of Carbon Dots in the Biological and Medical Field, Minnan Normal University, 2013.

[9] Z. Gao, G. Shen, X. Zhao et al., "Carbon dots: a safe nanoscale substance for the immunologic system of mice," Nanoscale Research Letters, vol. 8, no. 1, article 276, 2013.

[10] Y. Zhou, S. Cheng, H. Wei, and M. Sun, "A new toxicity test organism-Gobiocypris rarus," Journal of Zoological Systematics and Evolutionary Research, vol. 16, pp. 59-63, 1995.

[11] Z. Qun-Fang, J. Gui-Bin, and L. Ji-Yan, "Effects of sublethal levels of tributyltin chloride in a new toxicity test organism: the Chinese rare minnow (Gobiocypris rarus)," Archives of Environmental Contamination and Toxicology, vol. 42, no. 3, pp. 332-337, 2002.

[12] C. Schulte and R. Nagel, "Testing acute toxicity in the embryo of zebrafish, Brachydanio rerio, as an alternative to the acute fish test: preliminary results," Alternatives to Laboratory Animals Atla, vol. 22, no. 1, pp. 12-19, 1994.

[13] K. Końcaa, A. Lankoffb, A. Banasik et al., "A cross-platform public domain PC image-analysis program for the comet assay,"
Mutation Research/fundamental and Molecular Mechanisms of Mutagenesis, vol. 534, no. 1-2, pp. 15-20, 2003.

[14] K. J. Livak and T. D. Schmittgen, "Analysis of relative gene expression data using real-time quantitative PCR and the $2^{-\Delta \Delta C_{\mathrm{T}}}$ method," Methods, vol. 25, no. 4, pp. 402-408, 2001.

[15] M.-F. Chen, C.-Z. Huang, D.-Y. Pu et al., "Toxic effects of CdSe/ZnS QDs to zebrafish embryos," Environmental Science, vol. 36, no. 2, pp. 719-726, 2015.

[16] M.-S. Kim, K. M. Louis, J. A. Pedersen, R. J. Hamers, R. E. Peterson, and W. Heideman, "Using citrate-functionalized $\mathrm{TiO}_{2}$ nanoparticles to study the effect of particle size on zebrafish embryo toxicity," Analyst, vol. 139, no. 5, pp. 964-972, 2014.

[17] L. Lv, The Developmental Toxicity Study of nano-ZnO on Zebrafish Embryos, Harbin Institute of Technology, Harbin, China, 2013.

[18] P. Coutteau, M. R. Camara, and P. Sorgeloos, "The effect of different levels and sources of dietary phosphatidylcholine on the growth, survival, stress resistance, and fatty acid composition of postlarval Penaeus vannamei," Aquaculture, vol. 147, no. 3-4, pp. 261-273, 1996.

[19] A. J. Hill, S. M. Bello, A. L. Prasch, R. E. Peterson, and W. Heideman, "Water permeability and TCDD-induced edema in Zebrafish early-life stages," Toxicological Sciences, vol. 78, no. 1, pp. 78-87, 2004.

[20] Y. Wang, W. Dong, Z. Zhao et al., "Image quantitative assay of $\mathrm{Na}^{+} / \mathrm{K}^{+}$ATPase and cytochrome oxidase activity changes in lung tissue of rabbit with pulmonary edema after seawater drowning," Chinese Journal of Nautical Medicine, vol. 5, no. 2, pp. 90-92, 1998.

[21] T. C. King-Heiden, P. N. Wiecinski, A. N. Mangham et al., "Quantum dot nanotoxicity assessment using the zebrafish embryo," Environmental Science and Technology, vol. 43, no. 5, pp. 1605-1611, 2009.

[22] H. E. Hagenmaier, "The hatching process in fish embryos-IV. The enzymological properties of a highly purified enzyme (chorionase) from the hatching fluid of the rainbow trout, Salmo gairdneri rich," Comparative Biochemistry and Physiology-Part B, vol. 49, no. 2, pp. 313-324, 1974.

[23] J. Zong, Y. Zhu, X. Yang, J. Shen, and C. Li, "Synthesis of photoluminescent carbogenic dots using mesoporous silica spheres as nanoreactors," Chemical Communications, vol. 47, no. 2, pp. 764-766, 2011.

[24] J.-W. Xiong, A. Leahy, H.-H. Lee, and H. Stuhlmann, “Vezf1: a Zn finger transcription factor restricted to endothelial cells and their precursors," Developmental Biology, vol. 206, no. 2, pp. 123-141, 1999.

[25] J. Ge, Study on Funetion of Chiek Vascular Endothelial Zinc Finger-1 in Endothelial Cells Differentiation and Vessel Formation, Xiamen Normal University, 2009.

[26] R. Moreau, G. Daoud, A. Masse, L. Simoneau, and J. Lafond, "Expression and role of calcium-ATPase pump and sodiumcalcium exchanger in differentiated trophoblasts from human term placenta," Molecular Reproduction and Development, vol. 65, no. 3, pp. 283-288, 2003.

[27] J. M. Oldham, J. A. K. Martyn, M. Sharma, F. Jeanplong, R. Kambadur, and J. J. Bass, "Molecular expression of myostatin and MyoD is greater in double-muscled than normal-muscled cattle fetuses," American Journal of Physiology-Regulatory Integrative and Comparative Physiology, vol. 280, no. 5, pp. R1488-R1493, 2001.

[28] X. Zhu, S. Topouzis, L.-F. Liang, and R. L. Stotish, "Myostatin signaling through $S$ mad2, Smad3 and Smad 4 is regulated by the 
inhibitory Smad7 by a negative feedback mechanism," Cytokine, vol. 26, no. 6, pp. 262-272, 2004.

[29] X. Zhao and G. Duester, "Effect of retinoic acid signaling on Wnt $/ \beta$-catenin and FGF signaling during body axis extension," Gene Expression Patterns, vol. 9, no. 6, pp. 430-435, 2009.

[30] F.-I. Lu, C. Thisse, and B. Thisse, "Identification and mechanism of regulation of the zebrafish dorsal determinant," Proceedings of the National Academy of Sciences of the United States of America, vol. 108, no. 38, pp. 15876-15880, 2011.

[31] Y. Xiang, J. Gao, Z. Hu, and M. Zhou, "Category and function of Wnt gene," Chemistry of Life, vol. 27, no. 2, pp. 138-141, 2007.

[32] V. Milosavljevic, H. V. Nguyen, P. Michalek et al., "Synthesis of carbon quantum dots for DNA labeling and its electrochemical, fluorescent and electrophoretic characterization," Chemical Papers, vol. 69, no. 1, pp. 192-201, 2015.

[33] A. Nel, "Air pollution-related illness: effects of particles," Science, vol. 308, no. 5723, pp. 804-806, 2005.

[34] A. Nel, T. Xia, L. Mädler, and N. Li, “Toxic potential of materials at the nanolevel," Science, vol. 311, no. 5761, pp. 622-627, 2006.

[35] J. B. Pi, Q. Zhang, J. Fu et al., "ROS signaling, oxidative stress and Nrf2 in pancreatic beta-cell function," Toxicology and Applied Pharmacology, vol. 244, no. 1, pp. 77-83, 2010.

[36] S. K. Manna, S. Sarkar, J. Barr et al., "Single-walled carbon nanotube induces oxidative stress and activates nuclear transcription factor- $\kappa \mathrm{B}$ in human keratinocytes," Nano Letters, vol. 5, no. 9, pp. 1676-1684, 2005.

[37] L. Jiang, L.-L. Che, and D.-S. Xiao, "Gender differences in lipid peroxidation stress and anti-oxidation reaction in rat cardiac muscles by long-term swimming exercise," Journal of Clinical Rehabilitative Tissue Engineering Research, vol. 11, no. 47, pp. 9475-9478, 2007.

[38] L. Hao and L. Chen, "Oxidative stress responses in different organs of carp (Cyprinus carpio) with exposure to $\mathrm{ZnO}$ nanoparticles," Ecotoxicology and Environmental Safety, vol. 80, pp. 103-110, 2012.

[39] T. Gomes, J. P. Pinheiro, I. Cancio, C. G. Pereira, C. Cardoso, and M. J. Bebianno, "Effects of copper nanoparticles exposure in the mussel Mytilus galloprovincialis," Environmental Science and Technology, vol. 45, no. 21, pp. 9356-9362, 2011.

[40] Q. Rahman, M. Lohani, E. Dopp et al., "Evidence that ultrafine titanium dioxide induces micronuclei and apoptosis in Syrian hamster embryo fibroblasts," Environmental Health Perspectives, vol. 110, no. 8, pp. 797-800, 2002. 

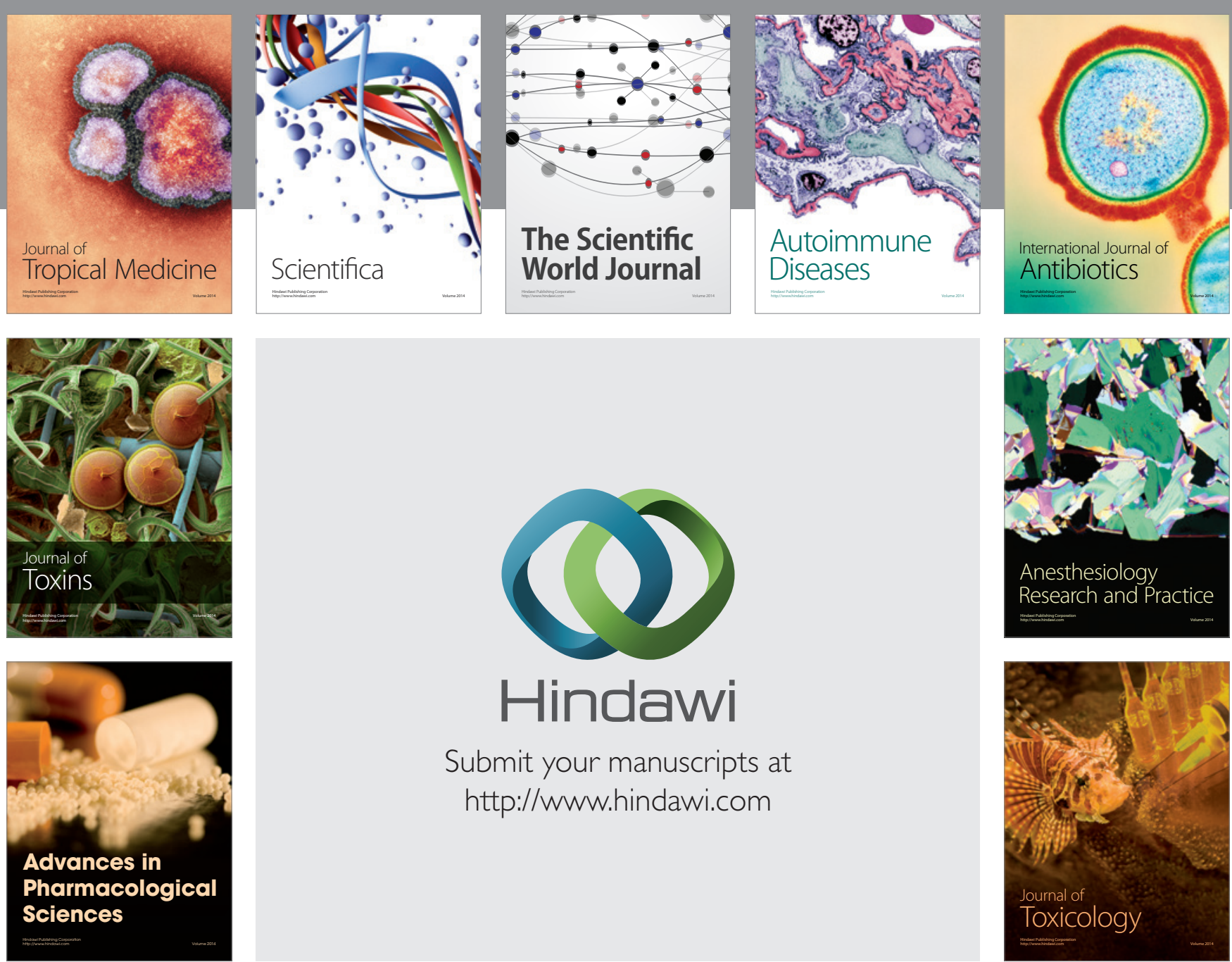

\section{Hindawi}

Submit your manuscripts at

http://www.hindawi.com
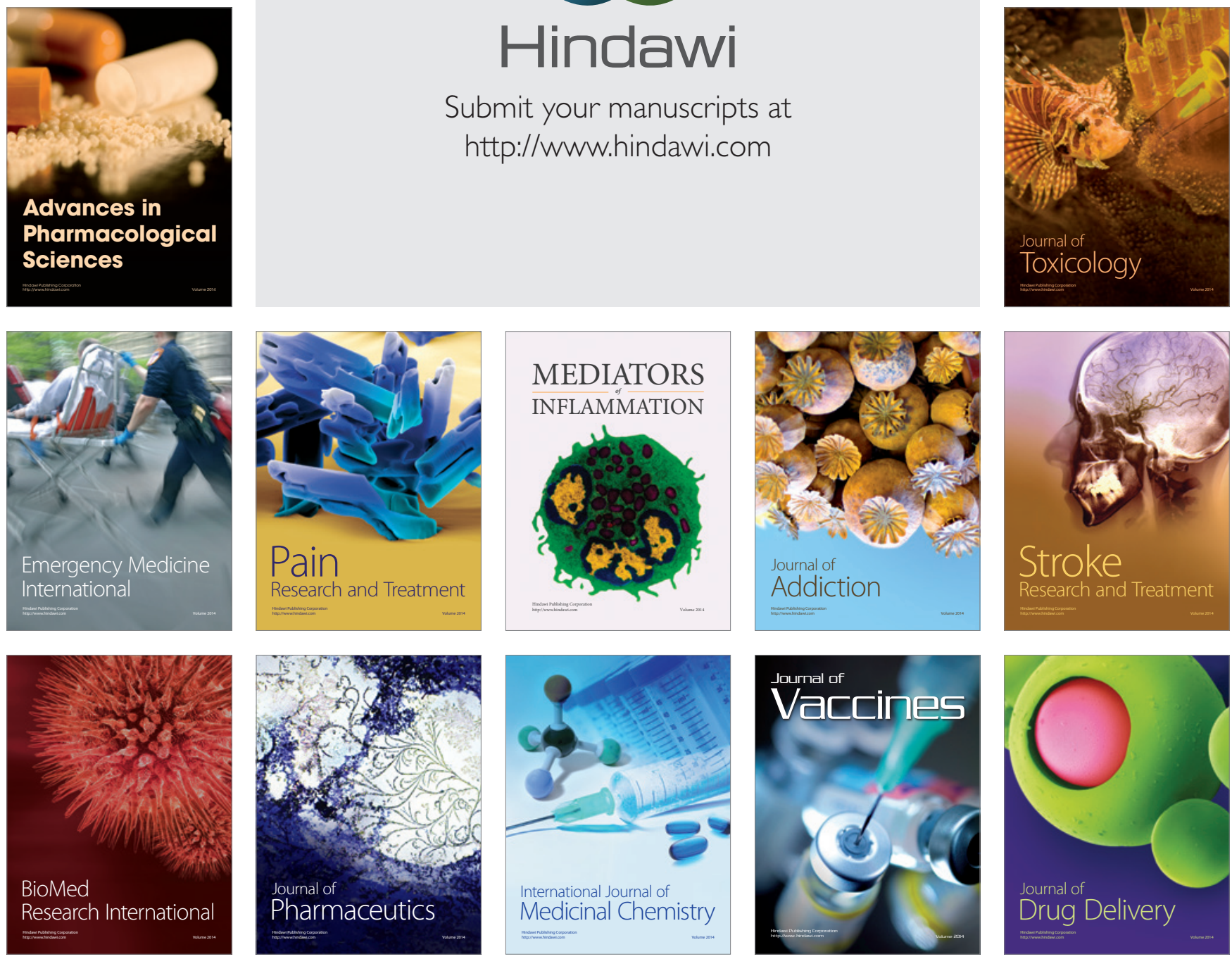